\title{
Endoscopic palliative management of esophageal and tracheal rupture
}

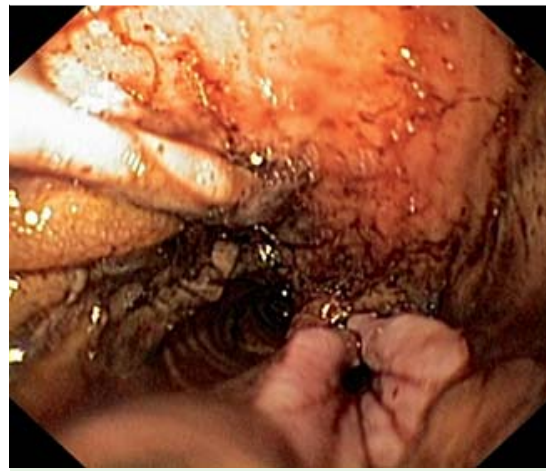

Fig. 1 Esophagogastroduodenoscopy revealed a huge esophageal perforation communicating with the trachea.

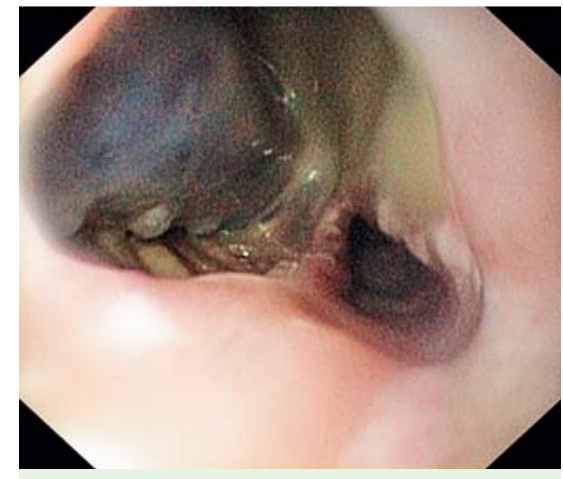

Fig. 2 Rigid bronchoscopy showing the tracheobronchial Dumon silicone Y-shaped stent in situ.

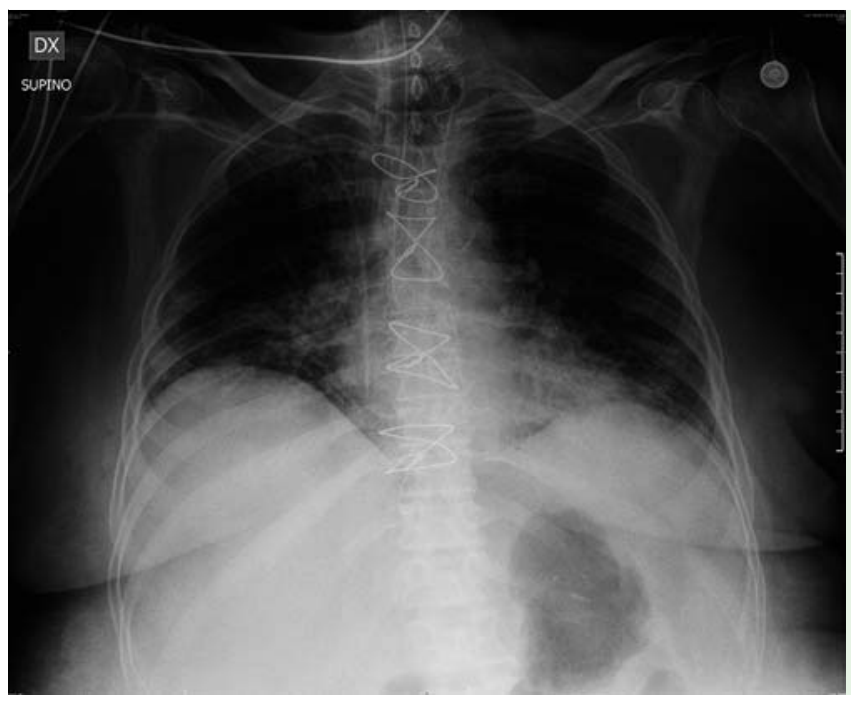

The increasing number of patients requiring intensive care and airway support has led to a growing recognition that significant short- and long-term morbidity may be associated with the use of artificial airways; this is despite significant improvements in the materials used in laryngeal tubes, which aim to decrease the trauma associated with long-term intubation [1]. We present the first case, to our knowledge, of huge, nontraumatic, esophageal perforation, widely communicating with the trachea, and which was treated successfully with double endoscopic stent placement.

A 62-year-old woman underwent quadruple coronary bypass surgery for critical
Fig. 4 Dumon stent in the trachea and covered, self-expandable, metal stent in the esophagus.

three-vessel disease and poor left ventricular function (Canadian Cardiovascular Society grade III, New York Heart Association grade III, American Society of Anesthesiologists grade III). The postoperative course was uneventful until the 18th postoperative day, when hematemesis occurred together with a drop in hemoglobin (from 12 to $10 \mathrm{~g} / \mathrm{dL}$ ) and hematocrit (35\% to $27 \%$ ) levels.

Emergency esophagogastroduodenoscopy revealed a Forrest III gastric antral ulcer and a complete gaping laceration of the middle esophagus $(3 \mathrm{~cm}$ in length and beginning $20 \mathrm{~cm}$ below the incisor teeth), which communicated with the trachea ( Fig.1). The patient had no

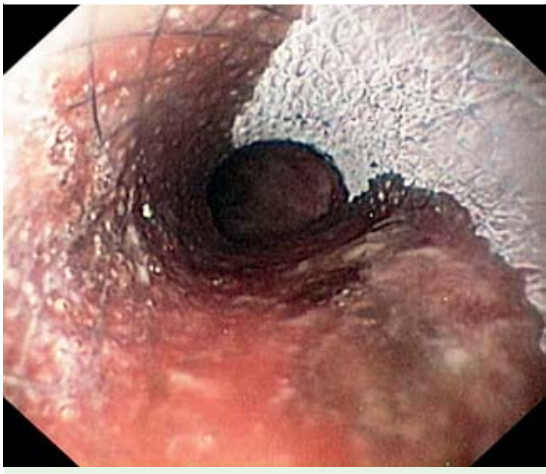

Fig.3 Esophagogastroduodenoscopy showing the covered nitinol self-expandable metal stent in situ.

symptoms of dyspnea, aspiration pneumonia or mediastinitis. Immediate rigid bronchoscopy with jet ventilation confirmed a 3-cm left tracheal gap, about $2.5 \mathrm{~cm}$ below the vocal folds and $4 \mathrm{~cm}$ above the carina. Thus, a tracheobronchial Dumon silicone Y-shaped stent (Tracheobronxane Dumon outer diameters 18-14-14 mm, length 110-50-50 mm; Novatech S.A., La Ciotat, France) was placed, in a position that avoided the upper lobar bronchus ( $\bullet$ Fig. 2 ). The patient was then re-intubated and placed in synchronized intermittent mandatory ventilation.

After 6 days (24th postoperative day), a polyurethane-covered nitinol self-expandable metal stent (Ultraflex Esophageal NG stent system, $12 \mathrm{~mm}$ in length; Boston Scientific, Natick, Massachusetts, USA) was positioned to restore esophageal continuity ( Fig.3).

The patient was discharged on the 30th postoperative day, with no symptoms of dysphagia, dyspnea, aspiration pneumonia or mediastinitis ( Fig.4). After 6 months, she died from cardiogenic shock. Delayed diagnosis of combined esophagotracheal lesions, especially when the trachea and esophagus merge into a huge cavity, as in the present case, make surgical repair particularly difficult [2]. In our opinion, etiology may be related to a huge tracheal lesion that develops during prolonged endotracheal intubation and is induced by cuff overinflation. 
Endoscopy_UCTN_Code_CPL_1AH_2AG

Competing interests: None

\section{Girolamo Geraci, Francesco Raffaele,} Giuseppe Modica, Carmelo Sciumè

Section of General and Thoracic Surgery, School of Medicine, University Hospital “Paolo Giaccone," Palermo, Italy

\section{References}

1 Sue RD, Susanto I. Long-term complications of artificial airways. Clin Chest Med 2003; 24: $457-471$

2 He J, Chen M, Shao W et al. Surgical management of huge tracheo-oesophageal fistula with oesophagus segment in situ as replacement of the posterior membranous wall of the trachea. Eur J Cardiothorac Surg 2009; 36: $600-602$

\section{Bibliography}

Dol http://dx.doi.org/

10.1055/s-0034-1377405

Endoscopy 2014; 46: E581-E582

(c) Georg Thieme Verlag KG

Stuttgart · New York

ISSN 0013-726X

\section{Corresponding author}

\section{Girolamo Geraci, MD, PhD}

Section of General and Thoracic Surgery School of Medicine

University Hospital "Paolo Giaccone"

Via Liborio Giuffrè 5 - 90127 Palermo

Italy

Fax: +39-091-6552774

girolamo.geraci@unipa.it 